\title{
Activation of transient receptor potential vanilloid 4 involves in hypoxia/reoxygenation injury in cardiomyocytes
}

\author{
Qiong-Feng Wu ${ }^{1,2,3,4,8}$, Cheng Qian ${ }^{1,2,3,4,8}$, Ning Zhao ${ }^{1,2,3,4,8}$, Qian Dong ${ }^{1,2,3,4}$, Jing Li ${ }^{1,2,3,4}$, Bin-Bin Wang ${ }^{1,2,3,4}$, Lei Chen ${ }^{5}$, \\ Lixiu Yu', Bing Han ${ }^{7}$, Yi-Mei Du*,1,2,3, and Yu-Hua Liao ${ }^{1,2,3,4}$
}

Transient receptor potential vanilloid 4 (TRPV4) is highly expressed in heart and vessels and can be activated during myocardial ischemia/reperfusion (I/R). Recently, we found that treatment with a selective TRPV4 antagonist HC-067047 significantly reduced infarct size, decreased troponin T levels and improved cardiac function in murine model myocardial I/R. This study was undertaken to investigate the mechanism underlying TRPV4-mediated myocardial I/R injury. To mimic myocardial I/R injury, we established a hypoxia/reoxygenation (H/R) model in $\mathrm{H} 9 \mathrm{C} 2$ cells and neonatal rat ventricle myocytes (NRVMs) in vitro. TRPV4 mRNA and protein expression was confirmed in the H9C2 and NRVM, whereas functional TRPV4 activity was assessed from $\mathrm{Ca}^{2+}$ influx response to a TRPV4 agonist GSK1016790A. TRPV4 functional expression was significantly enhanced during H/R. Furthermore, H/R increased the intracellular $\mathrm{Ca}^{2+}$ concentration $\left(\left[\mathrm{Ca}^{2+}\right]_{\mathrm{i}}\right)$ and induced cell injury, which were reversed by $\mathrm{HC}-067047$ but was further aggravated by GSK1016790A. Moreover, HC-067047 treatment significantly alleviated the increase of reactive oxygen species (ROS) generation, the depolarization of mitochondrial membrane potential $(\Delta y \mathrm{~m})$ and the opening of mitochondrial permeability transition pore (mPTP) during H/R. On the contrary, GSK1016790A exacerbated those effects. Meanwhile, increase in $\left[\mathrm{Ca}^{2+}\right]_{\mathrm{i}}$ and ROS induced by activation of TRPV4 was almost abolished when cells were cultured in $\mathrm{Ca}^{2+}$-free medium. In addition, ROS scavenger NAC obviously reversed activation of TRPV4-induced changes of $\Delta \psi \mathrm{m}$ and $\mathrm{mPTP}$ opening. Finally, we confirmed the direct roles of TRPV4 on cardiac injury and ROS generation in murine model myocardial I/R in vivo. In conclusion, activation of TRPV4 induces $\mathrm{Ca}^{2+}$ influx in cardiomyocytes, with subsequent ROS release, depolarizing of $\Delta \psi \mathrm{m}$, opening mPTP, inducing injury and TRPV4 has key roles during I/R via these pathways.

Cell Death and Disease (2017) 8, e2828; doi:10.1038/cddis.2017.227; published online 25 May 2017

TRPV4 belongs to the transient receptor potential vanilloid (TRPV) subfamily of transient receptor potential (TRP) cation channels. It is widely distributed in various organs and tissues including heart and vessels. ${ }^{1,2}$ TRPV4 may function as a molecular integrator of multiple chemical and physical stimuli, including hypotonic stimulation, cell swelling, moderate heat $\left(>24-37^{\circ} \mathrm{C}\right)$, endogenous metabolites of arachidonic acid and synthetic chemical ligands (such as GSK1016790A and $4 a$-PDD). ${ }^{3}$ Therefore, TRPV4 may have an important role in modulating the function of the cardiovascular system in physiological and pathological conditions. ${ }^{4}$

During myocardial ischemia/reperfusion (I/R), TRPV4 may be overactivated by cytotoxic edema or the metabolites of arachidonic acid, and it thus involves in myocardial I/R injury. ${ }^{5,6}$ Indeed, our previous study has demonstrated that treatment with a selective TRPV4 antagonist HC-067047 significantly reduced infarct size, decreased troponin $\mathrm{T}$ levels and improved cardiac function in murine model myocardial $\mathrm{I} / \mathrm{R}^{7}$ Increased activation of TRPV4 has been also observed in the hippocampus after cerebral I/R, whereas blocking TRPV4 attenuated I/Rinduced brain injury. ${ }^{8-11}$ Furthermore, sustained activation of TRPV4 dose-dependently induces apoptosis of retinal ganglion cells and neuronal death in the hippocampus. ${ }^{12,13}$ Therefore, TRPV4 may be a promising target to prevent myocardial I/R injury, but the mechanism underlying TRPV4-mediated myocardial I/R injury is still unclear.

TRPV4 is highly permeable to $\mathrm{Ca}^{2+}$. Activation of TRPV4 elicits $\mathrm{Ca}^{2+}$ influx and increases the intracellular concentration of free $\mathrm{Ca}^{2+}\left(\left[\mathrm{Ca}^{2+}\right]_{\mathrm{i}}\right){ }^{1,14}$ Furthermore, recent studies have found that TRPV4 agonists enhances the production of reactive oxygen species (ROS) via $\mathrm{Ca}^{2+}$ influx in endothelial cells, urothelial cell, macrophages, as well as hippocampus. ${ }^{15-18}$ In addition, $\mathrm{Ca}^{2+}$ overload and high level of ROS can trigger depolarization of mitochondrial membrane potential $(\Delta \psi \mathrm{m})$,

\footnotetext{
${ }^{1}$ Department of Cardiology, Union Hospital, Tongji Medical College, Huazhong University of Science and Technology, Wuhan, China; ${ }^{2}$ Research Center of lon Channelopathy, Union Hospital, Tongji Medical College, Huazhong University of Science and Technology, Wuhan, China; ${ }^{3}$ Institute of Cardiology, Union Hospital, Tongji Medical College, Huazhong University of Science and Technology, Wuhan, China; ${ }^{4}$ Key Lab for Biological Targeted Therapy of Education Ministry and Hubei Province, Union Hospital, Tongji Medical College, Huazhong University of Science and Technology, Wuhan, China; ${ }^{5}$ Department of Physiology, Nanjing Medical University, Nanjing, China; ${ }^{6}$ Department of Pharmacy, Union Hospital, Tongji Medical College, Huazhong University of Science and Technology, Wuhan, China and ${ }^{7}$ Department of Cardiology, Xuzhou Central Hospital, Xuzhou, China

${ }^{*}$ Corresponding author: Y-M Du, Department of Cardiology, Research Center of lon Channelopathy, Institute of Cardiology, Key Lab for Biological Targeted Therapy of Education Ministry and Hubei Province Research, Union Hospital, Tongji Medical College, Huazhong University of Science and Technology, Jiefang Avenue 1277, Wuhan, Hubei 430022, China. Tel: +86 27 85726462; Fax: +86 27 85755457; E-mail: yimeidu@ mail.hust.edu.cn

${ }^{8}$ These authors contributed equally to this work.

Received 16.2.17; revised 29.3.17; accepted 20.4.17; Edited by S Lavandero
} 
a

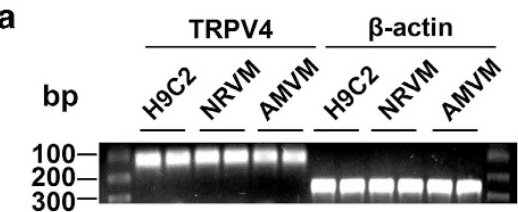

C
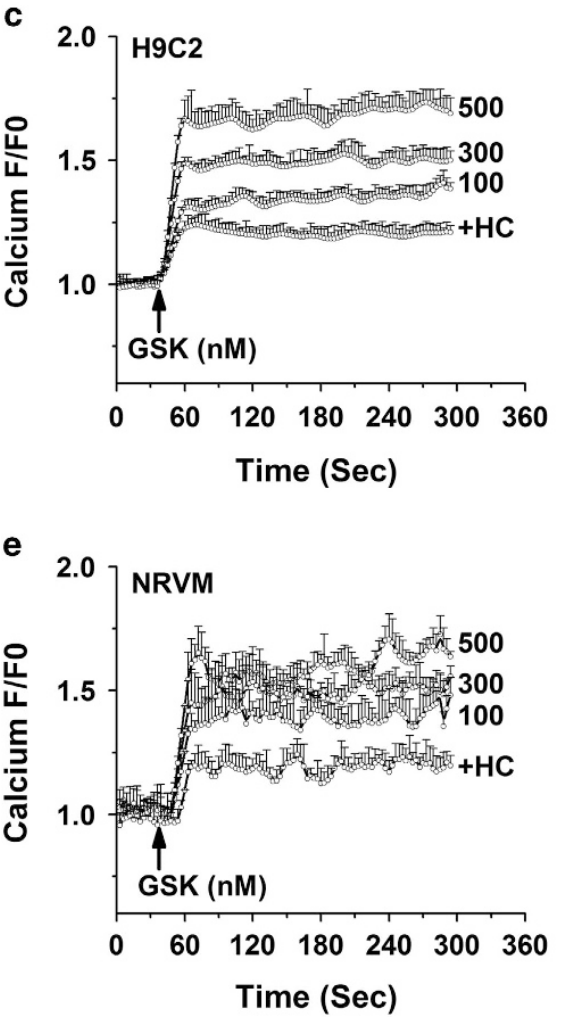

b

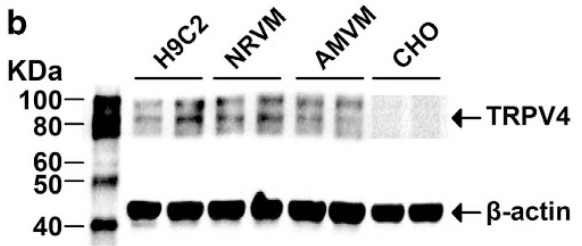

d

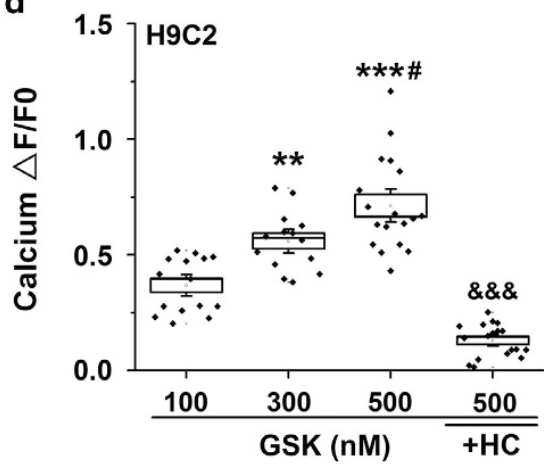

f

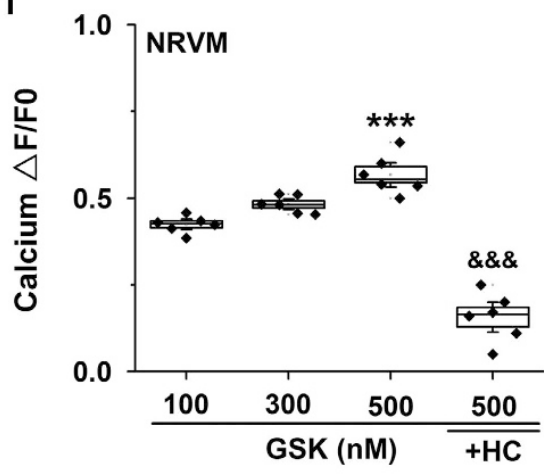

Figure 1 The functional expression of TRPV4 channel in cardiomyocytes. RT-PCR (a) and western blot analysis (b) showing the expression of TRPV4 mRNA and protein in H9C2, NRVM, AMVM and CHO. Representative graphs showing that the changes in $\left[\mathrm{Ca}^{2+}\right]_{\mathrm{i}}$ levels in H9C2 (c) and NRVM (e) in response to the TRPV4 agonist GSK1016790A $(100,300$ and $500 \mathrm{nM})$. Arrow indicates the addition of the stimulator. In some experiments, cells were pretreated with $1 \mu \mathrm{M} \mathrm{HC}-067047$ for 30 min. Quantitative analysis of relative changes $(\Delta \mathrm{F} / \mathrm{F} 0)$ in $\mathrm{Ca}^{2+}$ influx induced by GSK1016790A in H9C2 (d) and NRVM (f) loaded with Fluo-4/AM. The data are represented as mean \pm S.E.M. from $\geq 6$

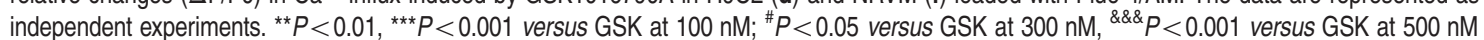

opening of the mitochondrial permeability transition pore (mPTP) and result in cell death, which contribute to myocardial I/R injury. ${ }^{19}$ Therefore, we hypothesized that TRPV4 activation exacerbates myocardial I/R injury via $\mathrm{Ca}^{2+} / \mathrm{ROS} / \mathrm{mPTP}$ pathway. To mimic myocardial I/R injury, we established a hypoxia/ reoxygenation $(\mathrm{H} / \mathrm{R})$ model in $\mathrm{H} 9 \mathrm{C} 2$ cells and neonatal rat ventricle myocytes (NRVMs) in vitro. Some of the results were confirmed in the murine model myocardial $\mathrm{I} / \mathrm{R}$ in vivo.

\section{Results}

TRPV4 is functional expressed in cardiomyocytes. We first determine whether TRPV4 is expressed in cardiomyocytes using RT-PCR and western blot techniques. As shown in Figure 1a, TRPV4 mRNA was detected positively at $108 \mathrm{bp}$ in $\mathrm{H} 9 \mathrm{C} 2, \mathrm{NRVM}$ and adult mice ventricle myocytes (AMVMs). Correspondingly, TRPV4 protein was presented with two obvious bands of molecular weights about 85 and $100 \mathrm{kDa}$ as expected, but absent in Chinese hamster ovary $(\mathrm{CHO})$ cells (Figure 1b). To further test whether TRPV4 is functionally active in cardiomyocytes, we loaded H9C2 and NRVM with Fluo-4/AM and measured $\mathrm{Ca}^{2+}$ influx in response to the specific TRPV4 agonist, GSK1016790A. GSK1016790A induced robust concentration-dependent (100, 300 and $500 \mathrm{nM}) \mathrm{Ca}^{2+}$ influx in $\mathrm{H} 9 \mathrm{C} 2$, which was almost blocked by pretreatment with a selective TRPV4 antagonist, HC-067047 $(1 \mu \mathrm{M})$ for $30 \mathrm{~min}$ (Figure 1c). Summary data were shown in Figure 1d. A similar $\mathrm{Ca}^{2+}$ response to GSK1016790A and $\mathrm{HC}-067047$ was observed in NRVM (Figures 1e and f). Taken together, our results show that TRPV4 is functionally expressed in cardiomyocytes.

The functional expression of TRPV4 is upregulated in cardiomyocytes subjected to H/R. As shown in Figures 2a-c, TRPV4 mRNA and protein expression levels markedly increased after 6-h hypoxia and maintained higher level at 1-h 

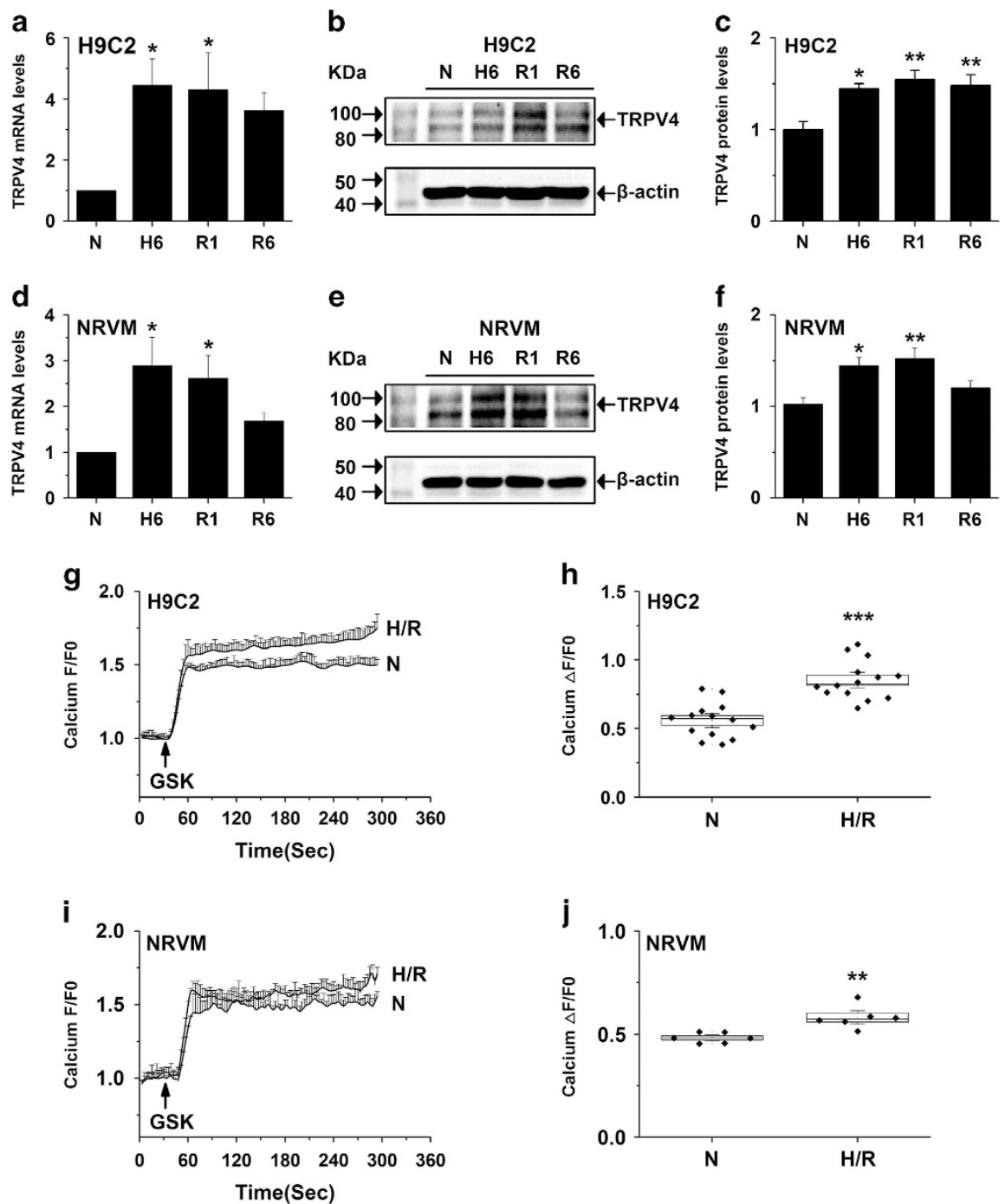

Figure 2 Upregulated functional expression of TRPV4 in cardiomyocytes after exposed to H/R. Real-time PCR analysis of TRPV4 mRNA in H9C2 (a) and at NRVM (d) at different times after H/R. Western blot analysis of TRPV4 protein in $\mathrm{H} 9 \mathrm{C} 2\left(\mathbf{b}\right.$ and $\mathbf{c}$ ) and at NRVM (e and $\mathbf{f}$ ) at different times after $\mathrm{H} / \mathrm{R}$. Representative graphs showing that $\mathrm{Ca}{ }^{2+}$ influx induced by GSK1016790A (300 nM) in H9C2 (g) and NRVM (i). Summary data for maximal increases in Ca ${ }^{2+}$ influx induced by GSK1016790A in H9C2 (h) and NRVM (j). The results shown are mean \pm S.E.M. from $\geq 6$ independent experiments. ${ }^{\star} P<0.05,{ }^{* \star} P<0.01,{ }^{\star \star \star} P<0.001$ versus $\mathrm{N}$

reoxygenation, but began to decrease at 6-h reoxygenation in H9C2. Similar results were observed in NRVM (Figures 2d-f). Same as previous observations, ${ }^{8,12}$ we found $\mathrm{H} / \mathrm{R}$ obviously increased the $\mathrm{Ca}^{2+}$ influx responses to $300 \mathrm{nM}$ GSK1016790A in H9C2 (Figure 2g) and NRVM (Figure 2i). Figures $2 \mathrm{~h}$ and $\mathrm{j}$ show the quantitative analysis of relative changes $(\triangle \mathrm{F} / \mathrm{F} 0)$ in $\mathrm{Ca}^{2+}$ influx at the steady state in $\mathrm{H} 9 \mathrm{C} 2$ and NRVM cells, respectively. Our results indicate that $H / R$ increases the functional expression of TRPV4.

Activation of TRPV4 contributes to $\mathrm{Ca}^{2+}$ overload in cardiomyocytes subjected to H/R. Consistent with previous reports, ${ }^{20,21} \mathrm{H} / \mathrm{R}$-induced $\left[\mathrm{Ca}^{2+}\right]_{\mathrm{i}}$ overload $(550.51 \pm 23.34 \mathrm{nM}$ versus $178.44 \pm 4.60 \mathrm{nM}, P<0.001$ versus $\mathrm{N}$ ), which can be reduced and enhanced by HC-067047 (285.91 $\pm 17.02 \mathrm{nM}$, $P<0.001$ versus $\mathrm{H} / \mathrm{R})$ and GSK1016790A $(922.59 \pm 51.43 \mathrm{nM}$, $P<0.001$ versus $\mathrm{H} / \mathrm{R}$ ) in $\mathrm{H} 9 \mathrm{C} 2$ (Figure $3 \mathrm{a}$ ), respectively. Similarly, $\left[\mathrm{Ca}^{2+}\right]_{i}$ was obviously elevated in NRVM (Figure $3 \mathrm{~b}$ ) subjected to $\mathrm{H} / \mathrm{R}(193.72 \pm 16.08 \mathrm{nM}$ versus $97.44 \pm 5.59 \mathrm{nM}$, $P<0.01$ versus $N$ ), which was significantly blunted in the presence of HC-067047 (120.87 $\pm 7.83 \mathrm{nM}, P<0.05$ versus $\mathrm{H} / \mathrm{R})$ and aggravated by GSK1016790 $(264.54 \pm 27.10 \mathrm{nM}$, $P<0.05$ versus $\mathrm{H} / \mathrm{R})$. Importantly, the increase $\left[\mathrm{Ca}^{2+}\right]_{\mathrm{i}}$ induced by GSK1016790 during H/R was completely abolished or strongly reduced when cells were cultured in $\mathrm{Ca}^{2+}$-free medium, consistent with the concept that the $\left[\mathrm{Ca}^{2+}\right]_{i}$ induced by activation of TRPV4 was mainly from extracellular $\mathrm{Ca}^{2+}$ influx. Interestingly, HC-067047 and GSK1016790A did not influence $\left[\mathrm{Ca}^{2+}\right]_{i}$ under normoxic conditions (Figures $3 a$ and b). Our results suggest that activation of TRPV4 involves in $\mathrm{H} /$ R-induced $\left[\mathrm{Ca}^{2+}\right]_{\mathrm{i}}$ overload in the cardiomyocytes.

Activation of TRPV4 involves in H/R-induced injury in cardiomyocytes. To test whether activation of TRPV4 involved in $\mathrm{H} / \mathrm{R}$-induced injury in cardiomyocytes, we investigated the effects of inhibition or activation of TRPV4 

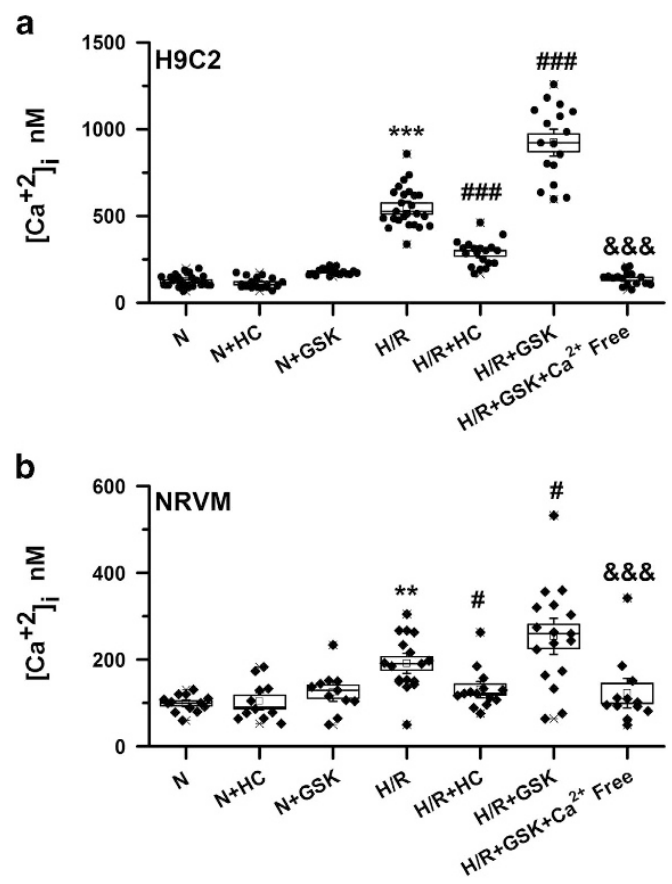

Figure 3 Effects of TRPV4 antagonist HC-067047 and TRPV4 agonist GSK1016790A on $\left[\mathrm{Ca}^{2+}\right]_{i}$ in H9C2 and NRVM subjected to $\mathrm{H} / \mathrm{R}$. $\left[\mathrm{Ca}^{2+}\right]_{i}$ was detected by fluorescent fluo-4/AM staining in H9C2 (a) and NRVM (b). Cultured cells were exposed to $\mathrm{H} / \mathrm{R}$ and incubated with HC-067047 $(1 \mu \mathrm{M})$ or GSK1016790A $(300 \mathrm{nM})$ during reoxygenation. The results are represented as mean \pm S.E.M. from $\geq 10$ independent experiments, ${ }^{* \star} P<0.01,{ }^{* \star} P<0.001$ versus $\mathrm{N}$; ${ }^{\#} P<0.05$ ${ }^{\# \#} P<0.001$ versus $\mathrm{H} / \mathrm{R}$; ${ }^{\text {\&\&\& }} P<0.001$ versus $\mathrm{H} / \mathrm{R}+\mathrm{GSK}$

on the H/R-induced change of cell morphology (Figure 4a), lactate dehydrogenase (LDH) release (Figure $4 b$ ), cell viability (Figure $4 \mathrm{c}$ ) and cell apoptosis (Figures $4 \mathrm{~d}$ and e) in H9C2 cells. In accord with previous reports, H/R-induced significant injuries in $\mathrm{H} 9 \mathrm{C} 2$ cells. Inhibition of TRPV4 by $1 \mu \mathrm{M}$ HC-067047 during reoxygenation obviously reduced the H/Rinduced injury, whereas activation of TRPV4 by $300 \mathrm{nM}$ GSK1016790A aggravated H/R-induced injury. Meanwhile, either HC-067047 or GSK1016790A did not show any obvious effects on cell morphology, LDH release, cell viability and cell apoptosis under normoxic condition. Interestingly, cell viability has obviously recovered when the cells were cultured in $\mathrm{Ca}^{2+}$-free medium during $\mathrm{H} / \mathrm{R}$.

TRPV4-mediated $\mathrm{Ca}^{2+}$ influx involves in cytoplasmic ROS generation following $\mathbf{H} / \mathbf{R}$. To test the hypothesis that TRPV4 activation may enhance oxidative injury during $H / R$, we quantified $\mathrm{O}^{2-}$ content using $\mathrm{DHE}$ staining. Original fluorescent images and the quantitative analysis have been shown in Figures $5 \mathrm{a}$ and $\mathrm{b}$, respectively. As expected, blockade TRPV4 by HC-067047 significantly attenuated $\mathrm{H} / \mathrm{R}$-induced increase in $\mathrm{O}^{2-}$ formation, whereas activation TRPV4 with GSK1016790A treatment further increased this effect. However, the enhancement effects on ROS generation in both in $\mathrm{H} / \mathrm{R}$ and $\mathrm{H} / \mathrm{R}+\mathrm{GSK} 1016790 \mathrm{~A}$ groups were almost abolished when the cells were cultured in $\mathrm{Ca}^{2+}$-free medium, suggesting that $\mathrm{Ca}^{2+}$ influx mediated by TRPV4 activation involves in the ROS generation during $H / R$. Either HC-067047 or GSK1016790A has no effects on ROS generation under normoxic conditions (Supplementary Figure S1).

ROS generation mediated by TRPV4 activation induces mPTP opening in cardiomyocytes subjected to $H / R$. We next sought to investigate downstream effectors of ROS that mediate TRPV4 activation induced injury in $\mathrm{H} 9 \mathrm{C} 2$ cells subjected to H/R. It has been shown that ROS involves in $\mathrm{H} / \mathrm{R}$-induced injury via effects on the depolarization of $\Delta \psi \mathrm{m}$ and the opening of mPTP. ${ }^{22} \Delta \psi \mathrm{m}$ was measured using JC-1 staining and calculated as the fluorescent ratio of red to green. The lower ratio illustrated the level of mitochondrial depolarization. As shown in Figures $6 \mathrm{a}$ and b, H/R-induced depolarization of $\Delta \psi \mathrm{m}$, which was partially reversed by HC-067047 treatment but further enhanced by GSK1016790A. Moreover, we detected the mPTP opening mode with the calcein-cobalt method. Consistent with the above results, HC-067047 blocked the H/R-induced mPTP opening, whereas GSK1016790A enhanced the H/R-induced mPTP opening (Figure 6c). As expected, $8 \mathrm{mM}$ NAC significantly restored $\triangle \Psi \mathrm{m}$ and inhibition of $\mathrm{MPTP}$ opening during $\mathrm{H} / \mathrm{R}$ and $\mathrm{H} / \mathrm{R}+\mathrm{GSK} 1016790 \mathrm{~A}$ (Figure 6). Thus, mPTP is an important downstream effector in the activation of TRPV4-ROS induced cardiotoxicity during H/R.

Activation of TRPV4 involves myocardial $1 / R$ injury in vivo. We further investigated the effects of inhibition or activation of TRPV4 on infarct size, serum cardiac troponin T (cTnT) level and heart function in myocardial I/R injury in vivo. Figure $7 \mathrm{a}$ showed representative photographs of heart tissues stained with Evans blue dye to delineate the area at risk (AAR) and TTC to delineate the infarct area (IA). Mice treated with HC-067047 showed a significantly reduced infarct size by $58 \%$ compared with vehicle $(15 \pm 1.4 \%$ versus $36 \pm 1 \%, P<0.001$; Figure 7c). In contrast, GSK1016790A group, the myocardial infarct size was greater compared with vehicle group $(46 \pm 1.76 \%, P<0.01$; Figure $7 \mathrm{c})$. AAR was similar among groups (Figure $7 \mathrm{~b}$ ). Furthermore, serum cardiac troponin $\mathrm{T}$ level, a marker of cardiac injury, was significantly lower in the HC-067047 group, but higher in the GSK1016790A group (Figure 7d). Consistent with infarct size, a marked improved of cardiac function, as shown by increases in ejection fraction (EF) and fractional shortening (FS) measured at $24 \mathrm{~h}$ after reperfusion, was observed in the HC-067047 group (Figures 7d and f). On the contrary, the EF and FS was remarkably reduced in GSK1016790A groups compared with vehicle group (Figures $7 e$ and f). Our results confirm the direct role of TRPV4 during myocardial I/R in vivo.

Activation of TRPV4 involves ROS generation during myocardial $\mathbf{I} / \mathbf{R}$ in vivo. We also measured the effects of inhibition or activation of TRPV4 on ROS generation in myocardial I/R injury in vivo (Figure 8). This results show that myocardial I/R significantly increased ROS levels, which was reduced by treatment with $\mathrm{HC}-076047$ but was enhanced by GSK1016790A. This was consistent with the results from the H9C2 cells in vitro. 
a
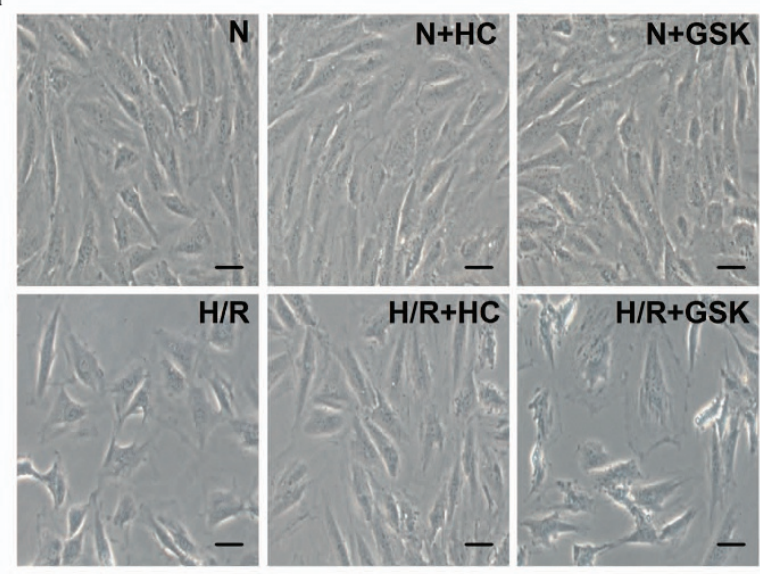

d

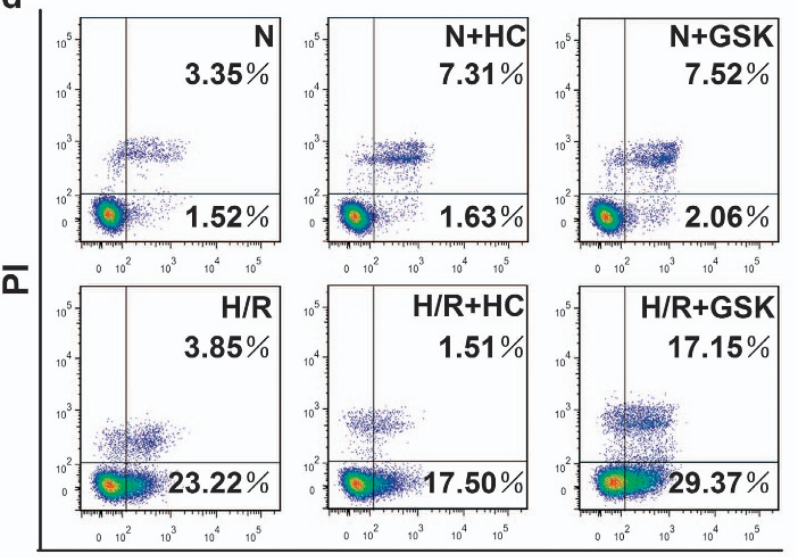

Annexin V

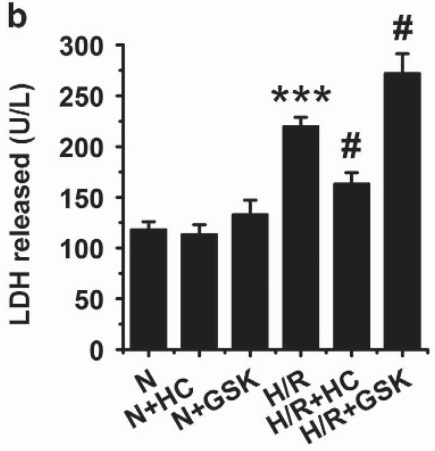

C
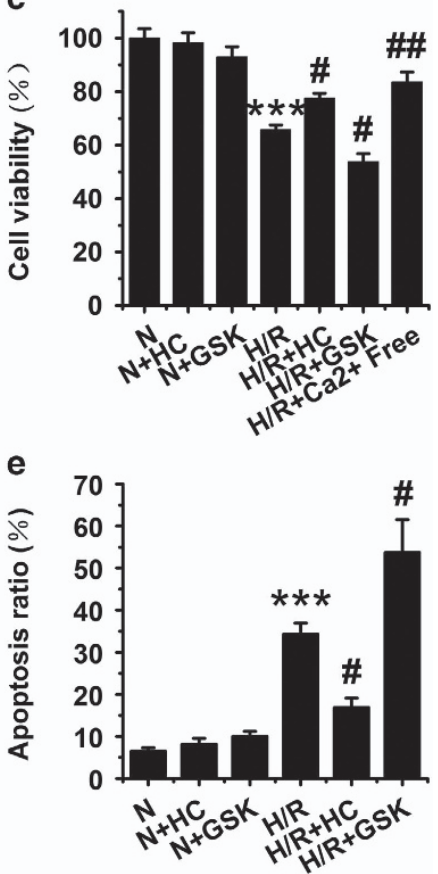

Figure 4 Effects of TRPV4 antagonist HC-067047 and TRPV4 agonist GSK1016790A on H/R-induced cell morphology change, LDH release, cell viability and apoptosis in H9C2 subjected to H/R. (a) Light microscopic images of morphological changes. Scar bar: $25 \mu \mathrm{m}$. (b) LDH release was measured by LDH assay kits. (c) Cell viability was detected using CCK-8 assay. Representative images (d) and quantitative analysis (e) of apoptotic rate was assessed as (Annexin V (+) PI (-) cells + Annexin V (+) PI (+) cells)/total cells $\times 100 \%$ using flow cytometry. Cultured cells were exposed to $\mathrm{H} / \mathrm{R}$ and incubated with HC-067047 (1 $\mu \mathrm{M})$ or GSK1016790A (300 nM) during reoxygenation. The results are represented as mean \pm S.E.M. from $\geq 6$ independent experiments. ${ }^{* * *} P<0.001$ versus $\mathrm{N},{ }^{*} P<0.05$ versus $\mathrm{H} / \mathrm{R}$

\section{Discussion}

TRPV4 is widely expressed in the cardiovascular system with functional existence in endothelial cells, smooth muscle cells and cardiac fibroblasts. ${ }^{23-27}$ Activation of TRPV4 has been found to be involved in cardiac remodeling, pulmonary hypertension, blood pressure regulation and congestive heart failure. ${ }^{28-32}$ Our previous study has highlighted that TRPV4 have important roles in myocardial I/R-induced injury. ${ }^{7}$ In this study, we explored the mechanism underlying TRPV4mediated myocardial I/R injury. Our results have shown that activation of TRPV4 induces $\mathrm{Ca}^{2+}$ influx in cardiomyocytes, with subsequent ROS release, depolarizing of $\Delta \psi \mathrm{m}$, opening mPTP, inducing injury and TRPV4 has key roles during myocardial I/R via these pathways.

Consistent with our previous observation in vivo myocardial I/R, we showed the levels of TRPV4 mRNA and protein increased in cultured cardiomyocytes during H/R. Correspondingly, a greater $\mathrm{Ca}^{2+}$ influx induced by TRPV4 agonist
GSK1016790A was observed in cultured cardiomyocytes after being exposed to $H / R$, indicating that the TRPV4 functional activity is enhanced during $\mathrm{H} / \mathrm{R}$. This increase in $\mathrm{Ca}^{2+}$ entry could have important functional consequences. $\mathrm{Ca}^{2+}$ entry mediated via TRPV4 has been reported to trigger apoptosis in several cells. For example, application of TRPV4 agonist promoted the dose-dependent apoptosis of retinal ganglion cells and neurons in the hippocampus. ${ }^{12,13}$ A similar finding of the increase TRPV4 expression and TRPV4-mediated $\mathrm{Ca}^{2+}$ entry has been described in neuronal injury after cerebral I/ $\mathrm{R}^{8,9}$ Therefore, we hypothesize that activation of TRPV4 involved in myocardial l/R-induced injury.

Although a number of $\mathrm{Ca}^{2+}$ entry pathways have been implicated in mediating cardiomyocyte $\mathrm{Ca}^{2+}$ overload following myocardial I/R, including the $\mathrm{Na}^{+} / \mathrm{Ca}^{2+}$ exchanger and the $\mathrm{L}$-type $\mathrm{Ca}^{2+}$ channel, there is still considerable controversy as to which pathways are critical in mediating this process. ${ }^{33-35}$ Elevated $\left[\mathrm{Ca}^{2+}\right]_{i}$ is believed to be a central mediator of 
a
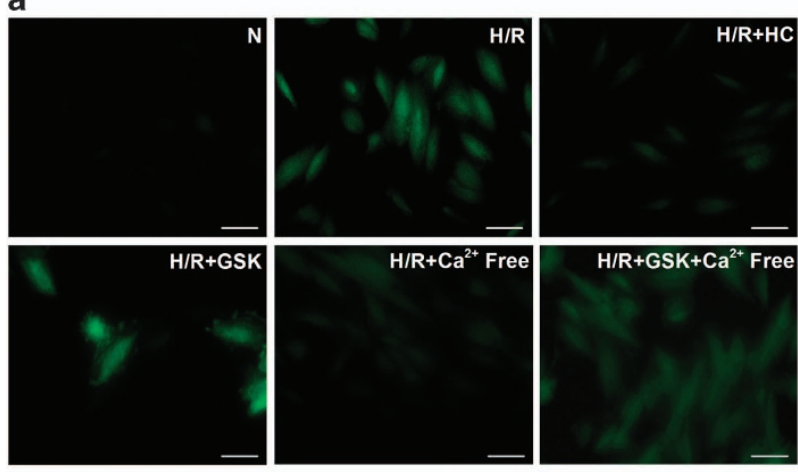

b

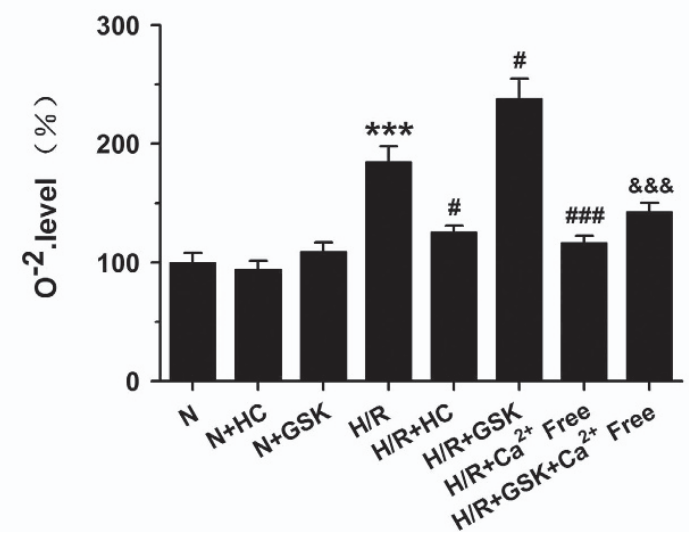

Figure 5 Effects of TRPV4 antagonist HC-067047 and TRPV4 agonist GSK1016790A on ROS generation in H9C2 subjected to H/R. Representative images (a) and quantitative analysis (b) of ROS generation was assessed by DCFHDA labeling using fluorescence microscopy and a Enspire multimode plate reader, respectively. Scar bar: $50 \mu \mathrm{m}$. The results are represented as mean \pm S.E.M. from $\geq 6$ independent experiments, ${ }^{* \star *} P<0.01$ versus $\mathrm{N}$; ${ }^{\#} P<0.05{ }^{\# \# \#} P<0.001$ versus $\mathrm{H} / \mathrm{R}$; \&\& $P<0.001$ versus $\mathrm{H} / \mathrm{R}+\mathrm{GSK}$

myocardial injury. ${ }^{35}$ In agreement with previous studies, we found that $\left[\mathrm{Ca}^{2+}\right]_{i}$ was increased in cultured $\mathrm{H} 9 \mathrm{C} 2$ and $\mathrm{CMs}$ after exposed $H / R$. We have also shown that TRPV4 antagonist HC-067047 markedly ameliorated H/R-induced injury in vitro as well as I/R-induced injury in vivo, consistent with attenuation of $\mathrm{H} / \mathrm{R}$-induced increase in $\left[\mathrm{Ca}^{2+}\right]_{\mathrm{i}}$. On the contrary, application TRPV4 agonist GSK1016790A exacerbated $\mathrm{H} / \mathrm{R}$ or $\mathrm{l} / \mathrm{R}$-induced injury, and meanwhile, accompanying additional increase in $\left[\mathrm{Ca}^{2+}\right]_{\mathrm{i}}$. Moreover, increase in $\left[\mathrm{Ca}^{2+}\right]_{i}$ induced by activation of TRPV4 during $\mathrm{H} / \mathrm{R}$ was almost abolished when cells were cultured in $\mathrm{Ca}^{2+}$-free medium. These results suggest that $\mathrm{Ca}^{2+}$ entry via TRPV4 may contribute to $\mathrm{Ca}^{2+}$ overload and injury following myocardial $\mathrm{l} / \mathrm{R}$.

Increase in ROS is also a key mediator of myocardial I/R injury. ${ }^{19,22}$ In this study, we found that TRPV4 antagonist $\mathrm{HC}-067047$ attenuated ROS increase in $\mathrm{H} 9 \mathrm{C} 2$ cells during H/R, however, TRPV4 agonist GSK1016790A treatment induced further increase, suggesting that TRPV4 may be involved in ROS production. In addition, activation TRPV4 induced ROS generation were almost abolished when cells were cultured in $\mathrm{Ca}^{2+}$-free medium, indicating that $\mathrm{Ca}^{2+}$ influx via TRPV4 seems the mainly contributor of ROS generation. Indeed, $\mathrm{Ca}^{2+}$ entry via TRPV4 has been shown to increase mitochondrial ROS production in many different cells. ${ }^{15-18}$ Activation of TRPV4 contributing to ROS production also confirmed in myocardial I/R injury.

Excessive ROS generation triggers the depolarization of $\triangle \Psi \mathrm{m}$ and the opening of MPTP, which initiates death pathways. Correspondingly, treatment the cells with HC-067047 and GSK1016790A during reoxygenation significantly alleviated and accelerated $\Delta \psi \mathrm{m}$ depolarization and mPTP opening, respectively. Meanwhile, ROS scavenger NAC obviously reversed TRPV 4 activation induced $\Delta \psi \mathrm{m}$ loss and $\mathrm{mPTP}$ opening during H/R. Thus, ROS are involved activation of TRPV4 induced $\triangle \psi m$ loss and mPTP opening during $\mathrm{H} / \mathrm{R}$.

In summary, our results show that $\mathrm{Ca}^{2+}$ entry via TRPV4 may involve in ROS production and then induce the depolarization of $\Delta \Psi \mathrm{m}$ and the opening of MPTP, finally lead to cell death and apoptosis during myocardial I/R injury. Our findings provide a novel cellular mechanism involved in the pathophysiology of myocardial I/R injury.

\section{Materials and Methods}

Cell isolation and culture. Both rat heart tissue-derived H9C2 cardiac myoblast cell line and $\mathrm{CHO}$ cell line from ATCC (Rockefeller, MD, USA) were cultured in Dulbecco's modified Eagle's medium (DMEM, Gibco, Grand Island, NY, USA, \#12800), supplemented with 15\% fetal bovine serum (FBS, Hangzhou Sijiqing Biological Engineering Materials Co., Ltd., Hangzhou, China) at $37^{\circ} \mathrm{C}$ in a humidified atmosphere of $95 \%$ air and $5 \% \mathrm{CO}_{2}$. NRVM were isolated from the whole heart of 1- to 2-day-old Sprague-Dawley rats using a modification of a previously described protocol. ${ }^{36,37}$ Briefly, hearts were minced, digested with enzymatic solution containing $0.1 \%$ (type II, Worthington Biochemical, Lakewood, NJ, USA) and $0.25 \%$ trypsin 1:250 (Amresco, Fountain Parkway Solon, OH, USA, \#0458) for 8 consecutive $7-10 \mathrm{~min}$ treatment periods at $37^{\circ} \mathrm{C}$. Cells were washed and then resuspended in $4.5 \mathrm{~g} / \mathrm{l}$ glucose DMEM supplemented with FBS, and 1\% penicillin/ streptomycin (v/v) and $100 \mu \mathrm{M}$ bromodeoxyuridine (Sigma, St. Louis, MO, USA \#858811) was added. AMVM were isolated from the heart of 8-12 weeks adult $\mathrm{C} 57 \mathrm{BL} / 6$ mice using a langendorff apparatus. After the animals were anesthetized with ether, their hearts were removed and retrograde perfusion through the aorta by $1 \mathrm{mg} / \mathrm{ml}$ collagenase type II for 10-15 min. H9C2 and NRVM were treated with a TRPV4 selective agonist GSK1016790A (Sigma-Aldrich, St. Louis, MO, USA) and a TRPV4 selective antagonist HC-067047 (Sigma-Aldrich, St. Louis, MO, USA) at the onset of reoxygenation.

H/R model. When NRVM and H9C2 cells reached $80 \%$ confluence, hypoxia was induced by replacing the air content with a $95 \% \mathrm{~N}_{2}$ and $5 \% \mathrm{CO}_{2}$ gas mixture in a controlled hypoxic plastic chamber (HiTech Photelectricity Biotechnology Co., Ltd, Guangzhou, China) and replacing the media with fresh $1.5 \mathrm{~g} / \mathrm{l}$ glucose DMEM (DMEM, Gibco, Grand Island, NY, USA) without serum for $6 \mathrm{~h}$. Subsequently, the medium was replaced by the normal media and incubated in $95 \%$ air and $5 \% \mathrm{CO}_{2}$ for $6-\mathrm{h}$ reoxygenation. Normal groups were cultured in normoxic conditions for corresponding times.

Reverse transcription (RT)-PCR amplification and quantitative (q) PCR. Total RNAs were extracted from cultured H9C2, NRVM and AMVM cells. And RT-PCR and $\mathrm{qPCR}$ was performed as described previously. ${ }^{38}$ Oligonucleotide sequences of primers specific for TRPV4 were TRPV4: 5'-CCCG AGAGAACACCAAGTTTG-3' (forward), and $5^{\prime}$-GACCGTCATTGTTAAGCACAGT CT-3' (reverse), and $\beta$-ACTIN: 5'-CGTTGACATCCGTAAAGACC-3' (forward), $5^{\prime}$-TAGAGCCACCAATCCACACA-3' (reverse). Amplified products were separated on $2 \%$ agarose gels in TAE buffer, visualized with $1 \mu \mathrm{g} / \mathrm{ml}$ ethidium bromide. The relative expression quantity $2^{-\Delta \Delta C t}$ value was calculated to compare the differences among groups. The result for each gene was obtained from at least six independent experiments.

Western blots. Total protein was extracted from the cultured H9C2, NRVM and AMVM as previous described. ${ }^{38}$ The protein concentrations in the supernatants 


\section{a}
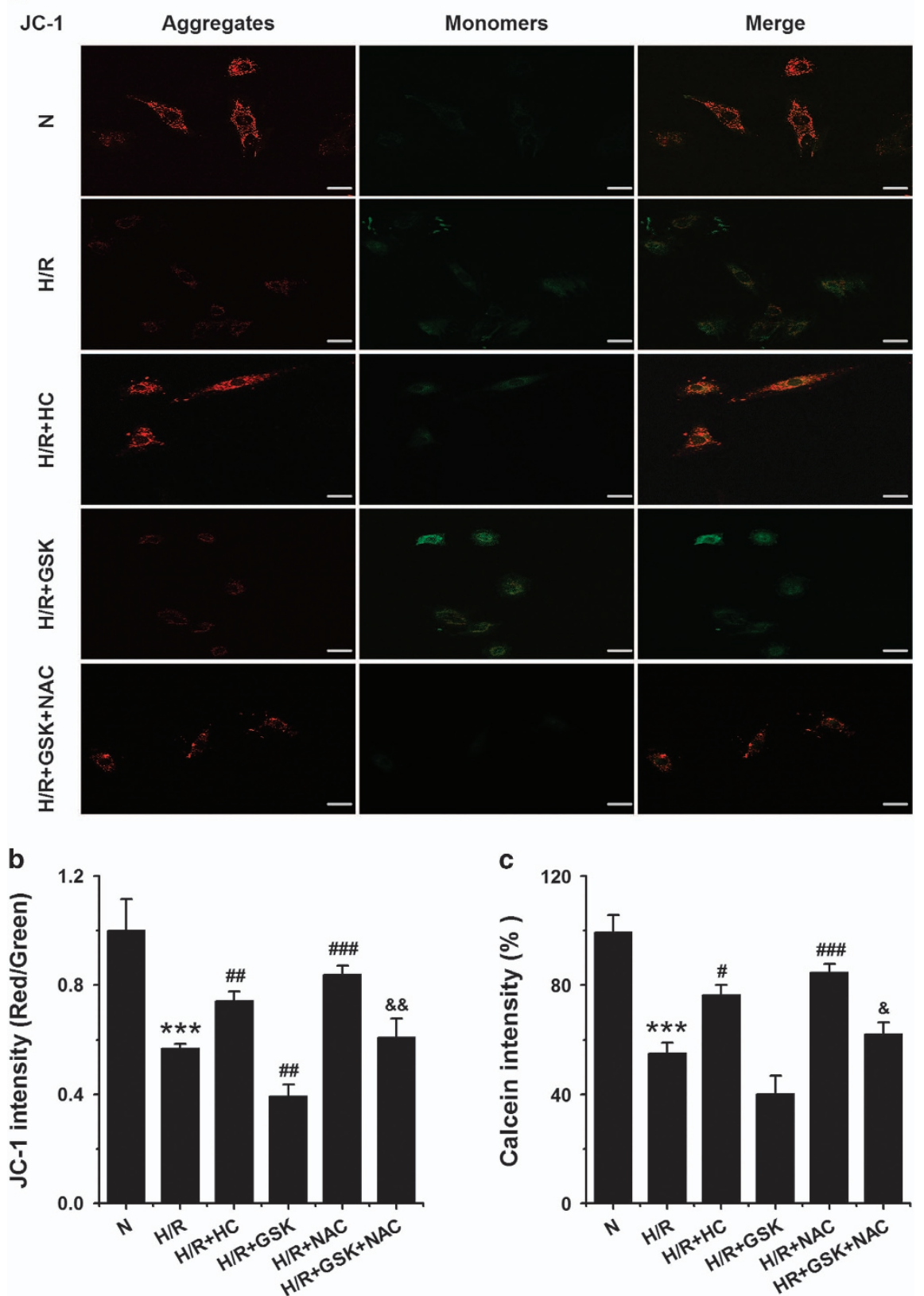

Figure 6 Effects of TRPV4 antagonist HC-067047 and TRPV4 agonist GSK1016790A on $\triangle$ Im and mPTP opening levels in H9C2 subjected to H/R. Representative images (a) and quantitative analysis (b) of $\Delta \Psi \mathrm{m}$ level was assessed by the lipophilic cationic probe JC-1 using fluorescence microscopy and a Enspire multimode plate reader, respectively. Scar bar: $50 \mu \mathrm{m}$ (c) mPTP opening was measured with the ratio of calcein fluorescences density using a Enspire multimode plate reader. The results are represented as mean \pm S.E.M. from $\geq 6$ independent experiments, ${ }^{* \star} P<0.001$ versus $\mathrm{N}$; ${ }^{\#} P<0.05, \# \# P<0.01,{ }^{\# \# \#} P<0.001$ versus $\mathrm{H} / \mathrm{R}$; ${ }^{\text {\& }} P<0.05$, ${ }^{\& \&} P<0.001$ versus $\mathrm{H} / \mathrm{R}+\mathrm{GSK}$

were measured using a BCA kit (Pierce, Rockford, IL, USA). Protein extracts $(20 \mu \mathrm{g})$ were run on $10 \%$ sodium dodecyl sulfate-polyacrylamide electrophoresis gels, and $10 \mu$ l biotinylated protein ladder (Cell Signaling Technology, Danvers, MA, USA, \#7727) loaded into a separate lane. Then, it was transferred to a nitrocellulose membrane by Electrophoresis System (Liu-Yi, Beijing, China). After being blocked with $5 \%$ nonfat milk for $2 \mathrm{~h}$, the membranes were incubated with the appropriate primary antibodies (Alomone Labs, Jerusalem, Israel, \#ACC-034) at $4{ }^{\circ} \mathrm{C}$ overnight, followed by incubation with a goat anti-rabbit IgG-HRP secondary antibody (Biossci, Wuhan, China, \#BB0820) anti-biotin HRP-linked antibody (Cell Signaling Technology, Danvers, MA, USA, \#7075) at a dilution of $1: 2000$. The protein expression levels were visualized using enhanced chemiluminescence method by Bio-Rad ChemiDoc XRS (Bio-Rad, Hercules, CA, USA) and quantified by Image Lab Software. $\beta$-Actin as an internal reference.
Intracellular calcium measurement. Intracellular calcium was measured as described previously. ${ }^{39,40}$ In brief, NRVM and H9C2 cells were loaded with $2 \mu \mathrm{M}$ Fluo-4/AM (Molecular Probes, Carlsbad, CA, USA, \#F14201) for $30 \mathrm{~min}$, washed three times with HEPES buffer that contained (in $\mathrm{mM}$ ) $130 \mathrm{NaCl}, 4.7 \mathrm{KCl}, 2.0$ $\mathrm{CaCl}_{2}, 1.2 \mathrm{MgSO}_{4}, 1.2 \mathrm{KH}_{2} \mathrm{PO}_{4}, 10 \mathrm{HEPES}$ and 11 glucose at $\mathrm{pH}$ 7.4. Cells in 96wells plate were illuminated at $488 \mathrm{~nm}$ and fluorescence emissions at $525 \mathrm{~nm}$ were captured with the Enspire Multimode Plate Reader (PerkinElmer, Boston, MA, USA). GSK1016790A (100, 300 and $500 \mathrm{nM})$ was used to induce $\mathrm{Ca}^{2+}$ influx. In some experiments, cells were pretreated with $1 \mu \mathrm{M} \mathrm{HC}-067047$ for 30 min. Changes in $\left[\mathrm{Ca}^{2+}\right]$ upon response to GSK1016790A were presented as relative changes (F/FO) or fold changes $(\Delta F / F 0)$, where $F$ is the fluorescence at intermediate $\mathrm{Ca}^{2+}$ levels, $\mathrm{F} 0$ is the average fluorescence before drug stimulation, $\Delta \mathrm{F}$ is the mean fluorescence after GSK1016790A stimulation at steady-state minus $\mathrm{F} 0 .\left[\mathrm{Ca}^{2+}\right]_{\text {i }}$ was calculated with the 
formula: $\left[\mathrm{Ca}^{2+}\right]_{i}=\mathrm{K}_{\mathrm{d}} \times\left(\mathrm{F} 0-\mathrm{F}_{\min }\right) /\left(\mathrm{F}_{\max }-\mathrm{F} 0\right)$; where $\mathrm{K}_{\mathrm{d}}$ is the dissociation constant ( $345 \mathrm{nM}$ for fluo-4), $F_{\min }$ is the fluorescence intensity of the indicator in the absence of $\mathrm{Ca}^{2+}$ and is obtained by adding a solution of $5 \mathrm{mM}$ EGTA for $15 \mathrm{~min}$, and $\mathrm{F}_{\max }$ is the fluorescence of the $\mathrm{Ca}^{2+}$ saturated indicator and is obtained by adding a solution of $0.1 \%$ Triton- $\mathrm{X} 100$ in $2.2 \mathrm{mM} \mathrm{CaCl}_{2}$ for $15 \mathrm{~min}$.

a
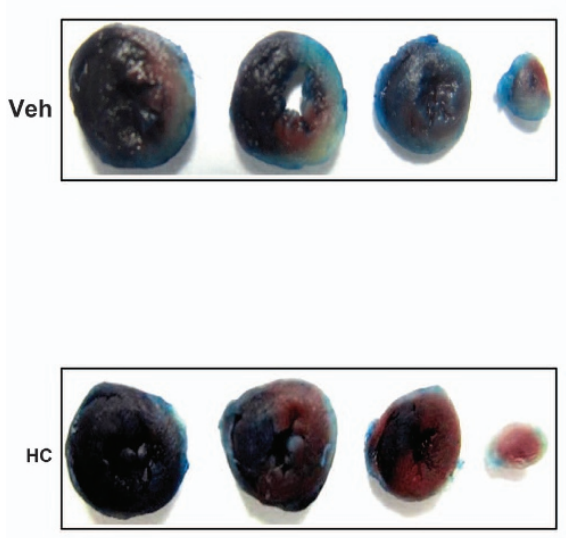

Measurement of LDH, cell viability and apoptosis. Cell death was quantified by analyzing LDH activity with commercial kits (JianCheng Bioengineering Institute, Nanjing, China, \#A020-2). Cell viability was measured using the Cell Counting Kit-8 (CCK-8, Dojindo Molecular Technologies, Kyushu, Japan, \#CK04) as previously described. ${ }^{38}$ Annexin $\mathrm{V}$ and PI fluorescein staining kit (eBioscience,
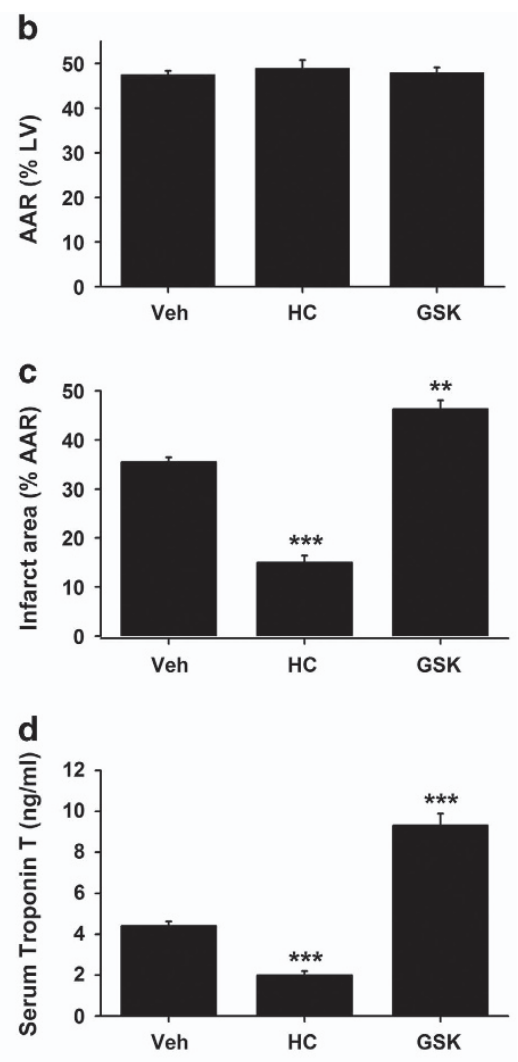

e

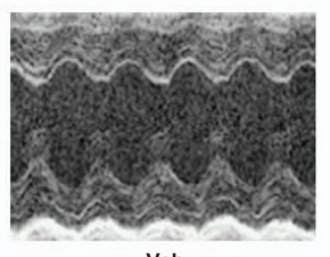

Veh

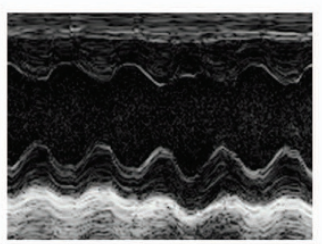

HC

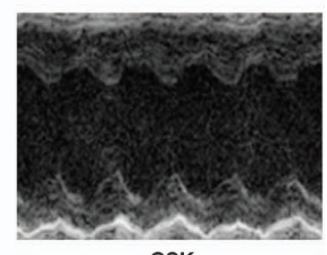

GSK

f
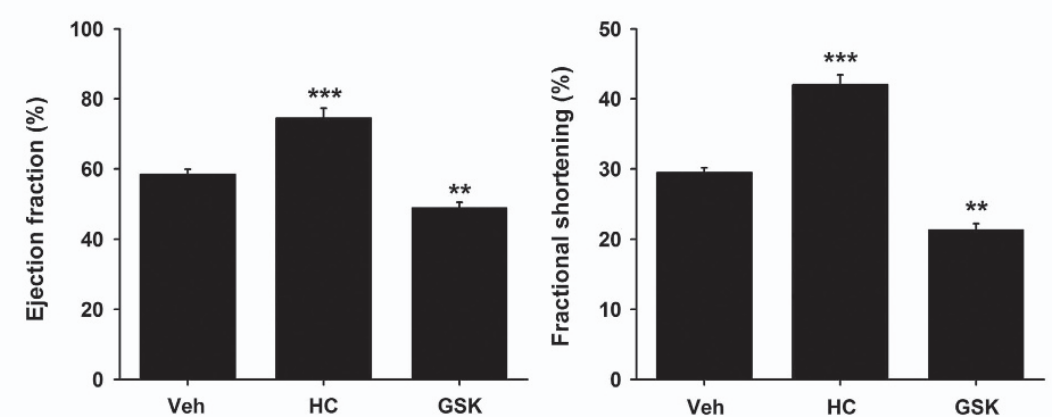

Figure 7 Effects of TRPV4 antagonist HC-067047 and TRPV4 agonist GSK1016790A on infarct size, serum cardiac troponin Tand heart function in a mice model of myocardial I/ R. (a) Representative images of LV slices from different groups at $24 \mathrm{~h}$ after reperfusion as stained by Evan's Blue and TTC. The non-ischemic area is indicated in blue, the AAR in red, and the IA in white. (b) Quantification of AAR (\%LV) at $24 \mathrm{~h}$ after reperfusion. (c) Quantification of infarct size of myocardial tissues at $24 \mathrm{~h}$ after reperfusion. (d) Serum concentration of TnT at $24 \mathrm{~h}$ after reperfusion. (e) Representative M-mode echocardiography images of the LV at $24 \mathrm{~h}$ after reperfusion. (f) Quantification of LV EF and FS. The TRPV4 antagonist HC-067047 (10 mg/kg) was intraperitoneally injected beginning at $1 \mathrm{~h}$ after reperfusion and then injected every $8 \mathrm{~h}$, and the TRPV4 agonist GSK1016790A (0.025 mg/kg) were administrated via jugular vein on the onset of reperfusion. The results are represented as mean \pm S.E.M., $n=6$ per group, ${ }^{* \star} P<0.01,{ }^{* \star \star} P<0.001$ versus Vehicle 


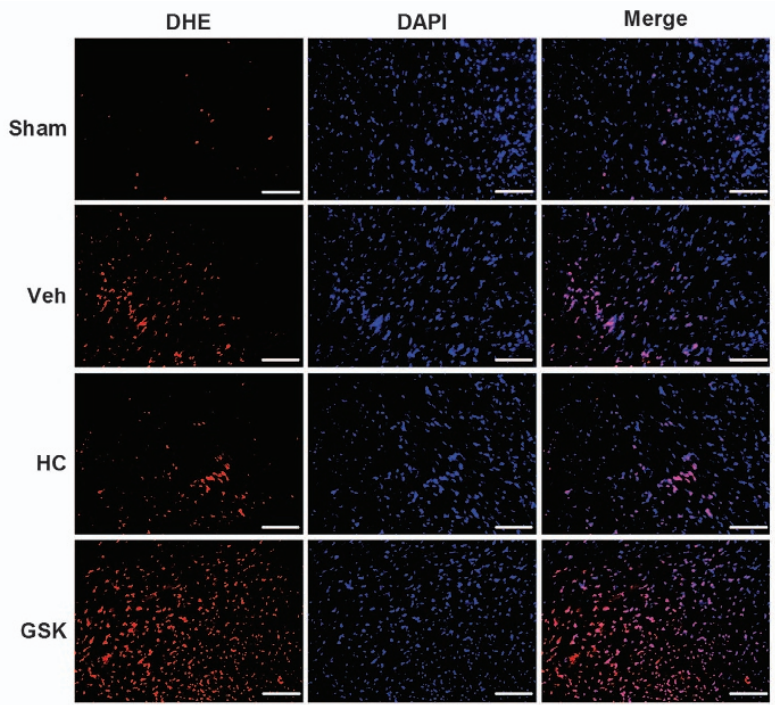

b

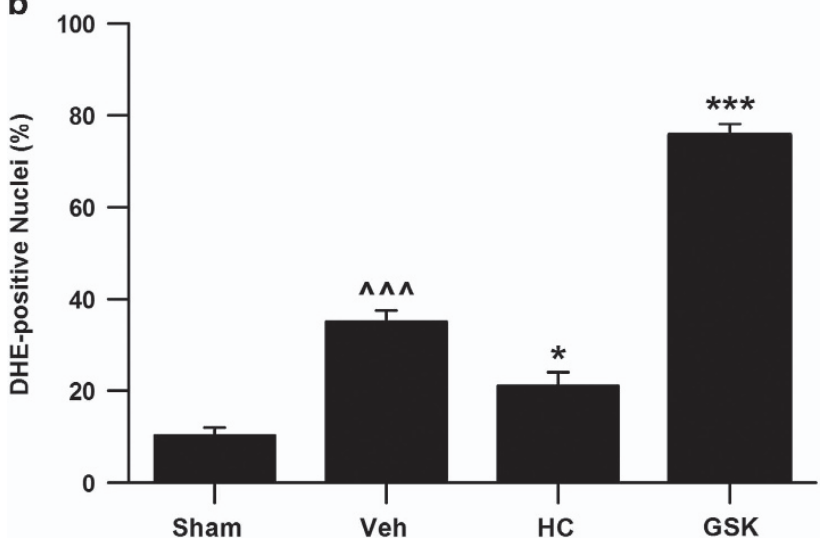

Figure 8 Effects of TRPV4 antagonist HC-067047 and TRPV4 agonist GSK1016790A on the cardiac oxidative stress in a mice model of myocardial I/R. (a) ROS production in the LV sections was evaluated with dihydroethidium (DHE) staining at $4 \mathrm{~h}$ after reperfusion. ROS-positive cells were identified by DHE staining (red), and total nuclei by DAPI staining (blue). Scale bar: $100 \mu \mathrm{m}$. (b) Quantitative analysis of ROS, as normalized to sham. The TRPV4 antagonist HC-067047 $(10 \mathrm{mg} / \mathrm{kg})$ was intraperitoneally injected beginning at $1 \mathrm{~h}$ after reperfusion and the TRPV4 agonist GSK1016790A $(0.025 \mathrm{mg} / \mathrm{kg})$ were administrated via jugular vein on the onset of reperfusion. $n=6-8$ per group, $M P<0.001$ versus Sham, ${ }^{*} P<0.05$, ${ }^{* * *} P<0.001$ versus Vehicle

SanDiego, CA, USA, \#BMS500FI) were utilized to measure apoptosis by following the manufacturer's instruction. Apoptosis rate was evaluated by Flow Cytometry (FACS Calibur, BD Biosciences, San Jose, CA, USA).

Measurement of intracellular ROS generation. ROS production in H9C2 was detected using the Reactive Oxygen Species Assay Kit (Beyotime Institute of Biotechnology, Nantong, China). Briefly, following treatment as mentioned in the section 'H/R model' above, the cells were incubated with DCFH-DA $(10 \mu \mathrm{M})$ at $37^{\circ} \mathrm{C}$ for $20 \mathrm{~min}$ in the dark. The fluorescence was detected by a fluorescent microscope or a Enspire Multimode Plate Reader (PerkinElmer, Boston, MA, USA) (488 nm excitation and $525 \mathrm{~nm}$ emission).

Changes in ROS from myocardium after I/R were detected with a fluorescent indicator dihydroethidium (DHE, Sigma-Aldrich). In brief, transverse croysections $(5 \mu \mathrm{m})$ of the left ventricle (LV) were incubated with $10 \mu \mathrm{M} \mathrm{DHE}$ for $30 \mathrm{~min}$ at $37^{\circ} \mathrm{C}$ followed by washing with PBS for three times. Nuclei were counterstained with DAPI for $5 \mathrm{~min}$ at room temperature. Images were obtained using an Olympus BX-51 epifluorescence microscope (Olympus, Tokyo, Japan). The numbers of DHE-positive nuclei was counted in five random fields in three nonconsecutive sections per heart at $\times 400$ magnification, and expressed as a percentage of the total number of DAPIstained nuclei.

Assessment of mitochondrial membrane potential $(\Delta \psi \mathrm{m})$. Changes of mitochondrial membrane potential $(\Delta \psi \mathrm{m})$ were measured by staining with JC-1 (Molecular Probes, Carlsbad, CA, USA, \#MP03168). After treatment, $\mathrm{H} 9 \mathrm{C} 2$ cells were incubated with $5 \mu \mathrm{M} \mathrm{JC}-1$ at $37^{\circ} \mathrm{C}$ for $30 \mathrm{~min}$. The fluorescence densities of the monomers (green, $485 / 530 \mathrm{~nm}$ ) and aggregates (red, $525 / 590 \mathrm{~nm}$ ) were detected with a fluorescent microscope or a Enspire Multimode Plate Reader. The ratio of aggregated JC-1 and monomeric JC-1 represented $\Delta \Psi \mathrm{m}$.

Analysis of mPTP opening with calcein. mPTP opening was assayed by measuring calcein (Molecular Probes, \#C3100MP) fluorescence quenched by cobalt chloride (Sigma, \#60818), as previously reported. In brief, H9C2 cells were loaded with $2 \mu \mathrm{M}$ calcein/AM and $2 \mathrm{mM} \mathrm{CoCl} 2$ at $37^{\circ} \mathrm{C}$ for $30 \mathrm{~min}$. After washing, cells were illuminated at $488 \mathrm{~nm}$ and an emission wavelength of $525 \mathrm{~nm}$ was captured with the Enspire Multimode Plate Reader every $30 \mathrm{~s}$. Results were expressed as a percentage of normoxic group.

In vivo mouse model of $\mathrm{I} / \mathrm{R}$ and treatment. Adult male C57BL/6 mice were obtained from VITAL RIVER (Beijing, China), bred and maintained on a chow diet in a 12-h light/12-h dark environment at $25^{\circ} \mathrm{C}$ in the Tongji Medical School Animal Care. All animal procedures were approved by the Institutional Animal Care and Use Committee, which is certified by Huazhong University of Science and Technology Committee on Animal Care. The surgical procedures of I/R were performed as previously described. ${ }^{7,41}$ Briefly, male C57BL/6 mice (22-23 g) were anesthetized by intraperitoneal injection of pentobarbital sodium $(50 \mathrm{mg} / \mathrm{kg}$ ), and the heart was exposed through a left thoracotomy at the forth intercostal space. The slipknot was tied around the left anterior descending coronary artery (LAD) 2-3 mm from its origin under a surgical microscope and released after $30 \mathrm{~min}$ of ischemia to allow reperfusion. Sham-operated (sham) animals were subjected to the same surgical procedures except that the slipknot was not tied.

The TRPV4 antagonist HC-067047 (10 mg/kg) was intraperitoneally injected beginning at $1 \mathrm{~h}$ after reperfusion and then injected every $8 \mathrm{~h}$, and the TRPV 4 agonist GSK1016790A $(0.025 \mathrm{mg} / \mathrm{kg})$ were administrated via jugular vein on the onset of reperfusion. The concentrations of the above-listed chemicals were selected based on previous reports. HC- 067047 were first dissolved in DMSO, and then diluted in $0.9 \% \mathrm{NaCl}$ solution. GSK1016790A was prepared in 1\% DMSO/20\% Captisol (sulfobutyl ether- $\beta$-cyclodextrin, Amresco) and saline. Vehicle mice were injected with the same volume of saline.

Determination of myocardical infarct size at the end of a $\mathbf{2 4 - h}$ reperfusion. Mice were briefly re-anesthetized at the end of a 24-h reperfusion, and the LAD was re-ligated and $1 \mathrm{ml}$ of $1 \%$ Evans Blue dye was infused into the aorta to delineate the AAR. The LV was isolated and cut into 1-mm-thick transverse slices. In order to differentiate infarcted from viable tissue, slices were incubated in $1 \%$ triphenyltetrazolium chloride (TTC, Sigma-Aldrich) in phosphate buffer at $\mathrm{pH} 7.4$ at $37^{\circ} \mathrm{C}$ for $10 \mathrm{~min}$, then they were fixed with $10 \%$ formaldehyde for $24 \mathrm{~h}$ and photos were taken. Regions negative for Evans Blue staining (AAR, red and white) and negative for TTC (IA, white) were calculated by a blinded observer using the computer-assisted planimetry function in ImageJ 6.0 ( $\mathrm{NIH}$, Bethesda, MD, USA). The myocardial infarct size was expressed as a percentage of IA over total AAR. Serum troponin $\mathrm{T}$ levels were evaluated as a biomarker for cardiac damage using a quantitative assay (Roche Diagnostics $\mathrm{GmbH}$, Mannheim, Germany) as previously described.

Echocardiographic analysis of cardiac function. A Vevo 2100 highresolution microimaging system with a $30 \mathrm{MHz}$ transducer was used (Visualsonic, Toronto, Ontario, Canada). Mice were anesthetized with $1.5 \%$ isoflurane and two-dimensional echocardiographic views of the mid-ventricular short axis and parasternal long axes were obtained. M-mode images were used to measure LV and LV EF and FS, which were acquired by a technician who was blinded to the treatment groups. Data analysis was performed using the Visualsonics data analysis suite.

Statistical analysis. All values are expressed as mean \pm S.E.M., and were analyzed for at least six independent experiments. Two-tailed $t$-tests or one-way ANOVA followed by Bonferroni's post-hoc test were performed to analyze differences with group comparison. Values of $P<0.05$ were considered statistically significant. 


\section{Conflict of Interest}

The authors declare no conflict of interest.

Acknowledgements. The authors thank Dr Jian-Fang Zhu for his technical assistance. This work was supported by the National Nature Science Foundation of China (81470421 to Y-MD), (81571270 to LC), (81503427 to LY; 91439207 to Y-HL) and the Science and Technology Department of Jiangsu Province (BK20131122 to BH).

1. Strotmann R, Harteneck C, Nunnenmacher K, Schultz G, Plant TD. OTRPC4, a nonselective cation channel that confers sensitivity to extracellular osmolarity. Nat Cell Biol 2000; 2: 695-702

2. Filosa JA, Yao X, Rath G. TRPV4 and the regulation of vascular tone. $J$ Cardiovasc Pharmacol 2013; 61: 113-119.

3. White JP, Cibelli M, Urban L, Nilius B, McGeown JG, Nagy I. TRPV4: molecular conductor of a diverse orchestra. Physiol Rev 2016; 96: 911-973.

4. Randhawa PK, Jaggi AS. TRPV4 channels: physiological and pathological role in cardiovascular system. Basic Res Cardiol 2015; 110: 54.

5. Nilius B, Prenen J, Wissenbach U, Bodding M, Droogmans G. Differential activation of the volume-sensitive cation channel TRP12 (OTRPC4) and volume-regulated anion currents in HEK-293 cells. Pflugers Arch 2001; 443: 227-233.

6. Watanabe H, Vriens J, Prenen J, Droogmans G, Voets T, Nilius B. Anandamide and arachidonic acid use epoxyeicosatrienoic acids to activate TRPV4 channels. Nature 2003; 424: 434-438.

7. Dong Q, Li J, Wu QF, Zhao N, Qian C, Ding D et al. Blockage of transient receptor potential vanilloid 4 alleviates myocardial ischemia/reperfusion injury in mice. Sci Rep 2017; 7: 42678.

8. Jie P, Lu Z, Hong Z, Li L, Zhou L, Li Y et al. Activation of transient receptor potential vanilloid 4 is involved in neuronal injury in middle cerebral artery occlusion in mice. Mol Neurobiol 2016; 53: 8-17.

9. Butenko O, Dzamba D, Benesova J, Honsa P, Benfenati V, Rusnakova V et al. The increased activity of TRPV4 channel in the astrocytes of the adult rat hippocampus after cerebral hypoxia/ischemia. PLOS ONE 2012; 7: e39959.

10. Li L, Qu W, Zhou L, Lu Z, Jie P, Chen L et al. Activation of transient receptor potential vanilloid 4 increases NMDA-activated current in hippocampal pyramidal neurons. Front $\mathrm{Ce}$ Neurosci 2013; 7: 17.

11. Jie $P$, Tian $Y$, Hong Z, Li L, Zhou L, Chen $L$ et al. Blockage of transient receptor potential vanilloid 4 inhibits brain edema in middle cerebral artery occlusion mice. Front Cell Neurosci 2015; 9: 141.

12. Ryskamp DA, Witkovsky P, Barabas P, Huang W, Koehler C, Akimov NP et al. The polymodal ion channel transient receptor potential vanilloid 4 modulates calcium flux, spiking rate, and apoptosis of mouse retinal ganglion cells. J Neurosci 2011; 31: 7089-7101.

13. Jie $P$, Hong $Z$, Tian $Y$, Li Y, Lin $L$, Zhou $L$ et al. Activation of transient receptor potential vanilloid 4 induces apoptosis in hippocampus through downregulating PI3K/Akt and upregulating p38 MAPK signaling pathways. Cell Death Dis 2015; 6: e1775.

14. Liedtke W, Choe Y, Marti-Renom MA, Bell AM, Denis CS, Sali A et al. Vanilloid receptorrelated osmotically activated channel (VR-OAC), a candidate vertebrate osmoreceptor. Cell 2000; 103: 525-535.

15. Donko A, Ruisanchez E, Orient A, Enyedi B, Kapui R, Peterfi Z et al. Urothelial cells produce hydrogen peroxide through the activation of Duox1. Free Radic Biol Med 2010; 49: 2040-2048.

16. Hamanaka K, Jian MY, Townsley MI, King JA, Liedtke W, Weber DS et al. TRPV4 channels augment macrophage activation and ventilator-induced lung injury. Am J Physiol Lung Cell Mol Physiol 2010; 299: L353-L362.

17. Hong Z, Tian Y, Yuan Y, Qi M, Li Y, Du Y et al. Enhanced oxidative stress is responsible for TRPV4-induced neurotoxicity. Front Cell Neurosci 2016; 10: 232.

18. Bubolz AH, Mendoza SA, Zheng X, Zinkevich NS, Li R, Gutterman DD et al. Activation of endothelial TRPV4 channels mediates flow-induced dilation in human coronary arterioles: role of $\mathrm{Ca}^{2+}$ entry and mitochondrial ROS signaling. Am J Physiol Heart Circ Physiol 2012; 302: $\mathrm{H} 634-\mathrm{H} 642$.

19. Sugamura K, Keaney JJ. Reactive oxygen species in cardiovascular disease. Free Radic Biol Med 2011; 51: 978-992.

20. Sun HY, Wang NP, Kerendi F, Halkos M, Kin H, Guyton RA et al. Hypoxic postconditioning reduces cardiomyocyte loss by inhibiting $\mathrm{ROS}$ generation and intracellular $\mathrm{Ca}^{2+}$ overload. Am J Physiol Heart Circ Physiol 2005; 288: H1900-H1908.

21. Sun HY, Wang NP, Halkos ME, Kerendi F, Kin H, Wang RX et al. Involvement of $\mathrm{Na}+/ \mathrm{H}_{+}$ exchanger in hypoxia/re-oxygenation-induced neonatal rat cardiomyocyte apoptosis. Eur J Pharmacol 2004; 486: 121-131.

22. Yellon DM, Hausenloy DJ. Myocardial reperfusion injury. N Engl J Med 2007; 357 : $1121-1135$.
23. Earley S, Heppner TJ, Nelson MT, Brayden JE. TRPV4 forms a novel $\mathrm{Ca}^{2+}$ signaling complex with ryanodine receptors and BKCa channels. Circ Res 2005; 97: 1270-1279.

24. Vriens J, Owsianik G, Fisslthaler B, Suzuki M, Janssens A, Voets T et al. Modulation of the $\mathrm{Ca}^{2+}$ permeable cation channel TRPV4 by cytochrome P450 epoxygenases in vascular endothelium. Circ Res 2005; 97: 908-915.

25. Yang XR, Lin MJ, McIntosh LS, Sham JS. Functional expression of transient receptor potential melastatin- and vanilloid-related channels in pulmonary arterial and aortic smooth muscle. Am J Physiol Lung Cell Mol Physiol 2006; 290: L1267-L1276.

26. Kohler R, Heyken WT, Heinau P, Schubert R, Si H, Kacik M et al. Evidence for a functional role of endothelial transient receptor potential V4 in shear stress-induced vasodilatation. Arterioscler Thromb Vasc Biol 2006; 26: 1495-1502.

27. Adapala RK, Thoppil RJ, Luther DJ, Paruchuri S, Meszaros JG, Chilian WM et al. TRPV4 channels mediate cardiac fibroblast differentiation by integrating mechanical and soluble signals. J Mol Cell Cardiol 2013; 54: 45-52.

28. Thorneloe KS, Cheung M, Bao W, Alsaid H, Lenhard S, Jian MY et al. An orally active TRPV4 channel blocker prevents and resolves pulmonary edema induced by heart failure. Sci Transl Med 2012; 4: 148r-159r.

29. Xia Y, Fu Z, Hu J, Huang C, Paudel O, Cai S et al. TRPV4 channel contributes to serotonininduced pulmonary vasoconstriction and the enhanced vascular reactivity in chronic hypoxic pulmonary hypertension. Am J Physiol Cell Physiol 2013; 305: C704-C715.

30. Yang XR, Lin AH, Hughes JM, Flavahan NA, Cao YN, Liedtke $W$ et al. Upregulation of osmo-mechanosensitive TRPV4 channel facilitates chronic hypoxia-induced myogenic tone and pulmonary hypertension. Am J Physiol Lung Cell Mol Physiol 2012; 302: L555-L568.

31. Feetham $\mathrm{CH}$, Nunn $\mathrm{N}$, Barrett-Jolley R. The depressor response to intracerebroventricular hypotonic saline is sensitive to TRPV4 antagonist RN1734. Front Pharmacol 2015; 6: 83.

32. Gao F, Sui D, Garavito RM, Worden RM, Wang DH. Salt intake augments hypotensive effects of transient receptor potential vanilloid 4: functional significance and implication. Hypertension 2009; 53: 228-235.

33. Du Y, Nathan RD. Ionic basis of ischemia-induced bradycardia in the rabbit sinoatrial node. J Mol Cell Cardiol 2007; 42: 315-325.

34. Du YM, Nathan RD. Simulated ischemia enhances L-type calcium current in pacemaker cells isolated from the rabbit sinoatrial node. AJP Heart Circ Physiol 2007; 293: H2986-H2994.

35. Garcia-Dorado D, Ruiz-Meana M, Inserte J, Rodriguez-Sinovas A, Piper HM. Calcium-mediated cell death during myocardial reperfusion. Cardiovasc Res 2012; 94: 168-180.

36. Huang Z, Chen XJ, Qian C, Dong Q, Ding D, Wu QF et al. Signal transducer and activator of transcription 3/microRNA-21 feedback loop contributes to atrial fibrillation by promoting atrial fibrosis in a rat sterile pericarditis model. Circ Arrhythm Electrophysiol 2016; 9: e003396.

37. Golden HB, Gollapudi D, Gerilechaogetu F, Li J, Cristales RJ, Peng X et al. Isolation of cardiac myocytes and fibroblasts from neonatal rat pups. Methods Mol Biol 2012; 843: 205-214.

38. Zhao N, Dong Q, Qian C, Li S, Wu QF, Ding D et al. Lovastatin blocks Kv1.3 channel in human T cells: a new mechanism to explain its immunomodulatory properties. Sci Rep 2015; 5: 17381.

39. Zhao N, Dong Q, Fu X, Du L, Cheng X, Du Y et al. Acacetin blocks Kv1.3 channels and inhibits human T cell activation. Cell Physiol Biochem 2014; 34: 1359-1372.

40. Fu X, Du L, Zhao N, Dong Q, Liao Y, Du Y. 18ß-Glycyrrhetinic acid potently inhibits Kv1.3 potassium channels and T cell activation in human Jurkat T cells. J Ethnopharmacol 2013; 148: $647-654$.

41. Liao YH, Xia N, Zhou SF, Tang TT, Yan XX, Lv BJ et al. Interleukin-17A contributes to myocardial ischemia/reperfusion injury by regulating cardiomyocyte apoptosis and neutrophil infiltration. J Am Coll Cardiol 2012; 59: 420-429.

(i) Cell Death and Disease is an open-access journal published by Nature Publishing Group. This work is licensed under a Creative Commons Attribution 4.0 International License. The images or other third party material in this article are included in the article's Creative Commons license, unless indicated otherwise in the credit line; if the material is not included under the Creative Commons license, users will need to obtain permission from the license holder to reproduce the material. To view a copy of this license, visit http://creativecommons.org/licenses/by/4.0/

(C) The Author(s) 2017 